Howell N, Kubacka I, Halvorson S, Mackey D (1993) Leber's hereditary optic neuropathy: the etiological role of a mutation in the mitochondrial cytochrome b gene. Genetics 133: 133-136

Johns DR, Berman J (1991) Alternative, simultaneous complex I mitochondrial DNA mutations in Leber's hereditary optic neuropathy. Biochem Biophys Res Commun 174:13241330

Mackey DA, Oostra R-J, Rosenberg T, Nikoskelainen E, Bronte-Stewart J, Poulton J, Harding AE, et al (1996) Primary pathogenic mtDNA mutations in multigeneration pedigrees with Leber hereditary optic neuropathy. Am J Hum Genet 59:481-485

Obermaier-Kusser B, Lorenz B, Schubring S, Paprotta A, Zerres K, Meitinger T, Meire F, et al (1994) Features of mtDNA mutation patterns in European pedigrees and sporadic cases with Leber hereditary optic neuropathy. Am J Hum Genet 55:1063-1066

Polymeropoulos MH, Swift RG, Swift M (1994) Linkage of the gene for Wolfram syndrome to markers on the short arm of chromosome 4. Nat Genet 8:95-97

Rödel G, Laubhan R, Scheuerle A, Skowronek P, Haferkamp O (1996) Association of the LHON 13708 and 15257 mitochondrial DNA mutations with neurodegenerative diseases distinct from LHON. Eur J Med Res 1:491-494

Torroni A, Carelli V, Petrozzi M, Terracina M, Barboni P, Malpassi P, Wallace DC, et al (1996a) Detection of the mtDNA 14484 mutation on an African-specific haplotype: implications about its role in causing Leber hereditary optic neuropathy. Am J Hum Genet 59:248-252

Torroni A, Huoponen K, Francalacci P, Petrozzi M, Morelli L, Scozzari R, Obinu D, et al (1996b) Classification of European mtDNAs from an analysis of three European populations. Genetics 144:1835-1850

Torroni A, Lott MT, Cabell MF, Chen Y-S, Lavergne L, Wallace DC (1994) mtDNA and the origin of Caucasians: identification of ancient Caucasian-specific haplogroups, one of which is prone to a recurrent somatic duplication in the Dloop region. Am J Hum Genet 55:760-776

Address for correspondence and reprints: Dr. Sabine Hofmann, Institute für Klinische Chemie und Diabetesforschung, Krankenhaus Munchen-Schwabing, Kölner Platz 1, 80804 München, Germany. E-mail: diabetes@lrz.unimuenchen.de

(C) 01997 by The American Society of Human Genetics. All rights reserved. 0002-9297/97/6006-0034\$02.00

Am. J. Hum. Genet. 60:1542-1544, 1997

\section{A Mutation in the MTM1 Gene Invalidates a Previous Suggestion of Nonallelic Heterogeneity in X-Linked Myotubular Myopathy}

To the Editor:

We reported previously in the Journal (Samson et al. 1995, p. 120) the study of a family with a single case of myotubular myopathy, in which linkage analysis, combined with examination of muscle biopsies in $\mathrm{fe}$ males for determination of carrier status, led us to "strongly suggest genetic heterogeneity" of this Xlinked disease, which previously had been mapped to Xq28 (MTM1 locus; OMIM 310400; Dahl et al. 1995; for a review, see Wallgren-Pettersson et al. 1995). Very recently, we have identified an Xq28 gene, coding for a putative tyrosine phosphatase, that was found mutated in many patients with X-linked myotubular myopathy (J. Laporte, unpublished data). We decided to reanalyze family $Z$ for the markers closest to this gene and to search for a mutation in the proband, using SSCP analysis on the exons that have been characterized to date (Laporte et al. 1996). We report here that a missense mutation indeed was found in the proband but was not present in his mother and in three other females thought to be carriers (see fig. 1), on the basis of detection of some small fibers with centrally located nuclei in the muscle biopsies of these individuals.

In our previous analysis, we reported that the unaffected boy (III.6) had inherited the same maternal alleles at the FRAXAC2 and DXS305 loci flanking MTM1 as were seen in the proband (III.4) and his putative carrier sister (III.3). However, a double recombination within FRAXAC2-DXS305, an interval of $\sim 10 \mathrm{cM}$, could not be formally excluded (Samson et al. 1995). The study of three microsatellite markers much closer to the MTM1 gene (Hu et al. 1996a; Laporte et al. 1996) now confirms that the same haplotype indeed was transmitted to all four children of II. 4 and also is present in the putative carriers (II.1 and II.2).

SSCP analysis was performed on five exons covering $752 \mathrm{bp}$ of coding sequence. For the exon encoding amino acids 370-438 (exon c, according to Laporte et al. 1996), we found four different band patterns (fig. 2). Sequencing of variant bands revealed the presence of two base-pair changes in the $5^{\prime}$ end of the following intron, defining three alleles (fig. 3). Alleles 1 and 2 differ at the consensus donor site and are common variants in the normal population (J. Laporte, unpublished data). Allele 3 , with an additional intronic change, is much rarer. It is present in the grandmother and also in III.2, in the latter of whom it must derive from the married-in father. It is thus also a polymorphism. The fourth variant was detected only in the proband (and, notably, was absent in his mother), when slow electrophoretic migration was used, conditions in which the $1 / 2$ polymorphism is barely detectable (fig. $2 a$ and $b$ ). On direct sequencing, we found an exonic single-base-pair change, A1244G. This results in a change of tyrosine 415 to a cysteine, in the predicted protein, called "myotubularin." This 


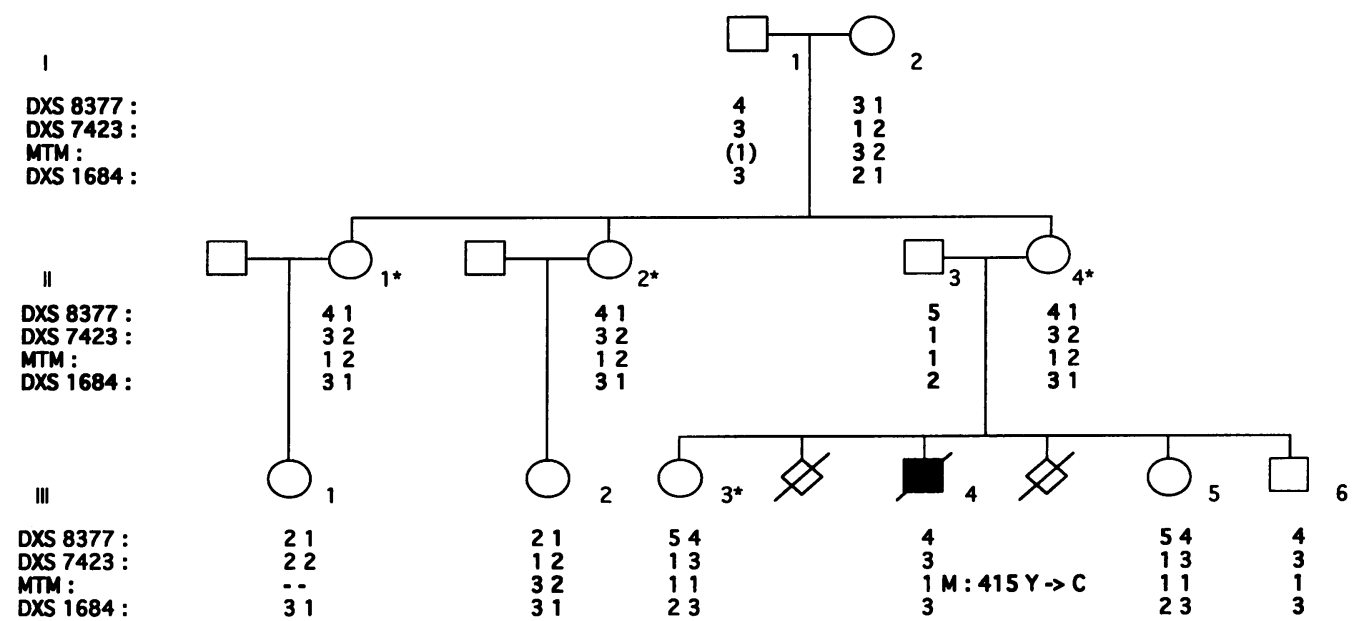

Figure 1 Pedigree of family Z. Genotypes are indicated for the microsatellites DXS8377, DXS7423, and DXS1684, which flank the MTM1 gene (Laporte et al. 1996). At the latter locus, normal alleles 1-3 correspond to variant intronic sites immediately following exon c (allele 1 was deduced in the grandfather [I.1]). The new mutation in III.4 occurred on the MTM allele 1 background. Females II.1, II.2, II.4, and III.3 (indicated by asterisks [ $\left.{ }^{*}\right]$ ) were thought to be carriers, on the basis of examination of muscle biopsies.

tyrosine residue is close to the putative tyrosine phosphatase active site (positions 389-402) and is conserved in the homologs of myotubularin, in both the yeast Saccharomyces cerevisiae and the worm Caeno-
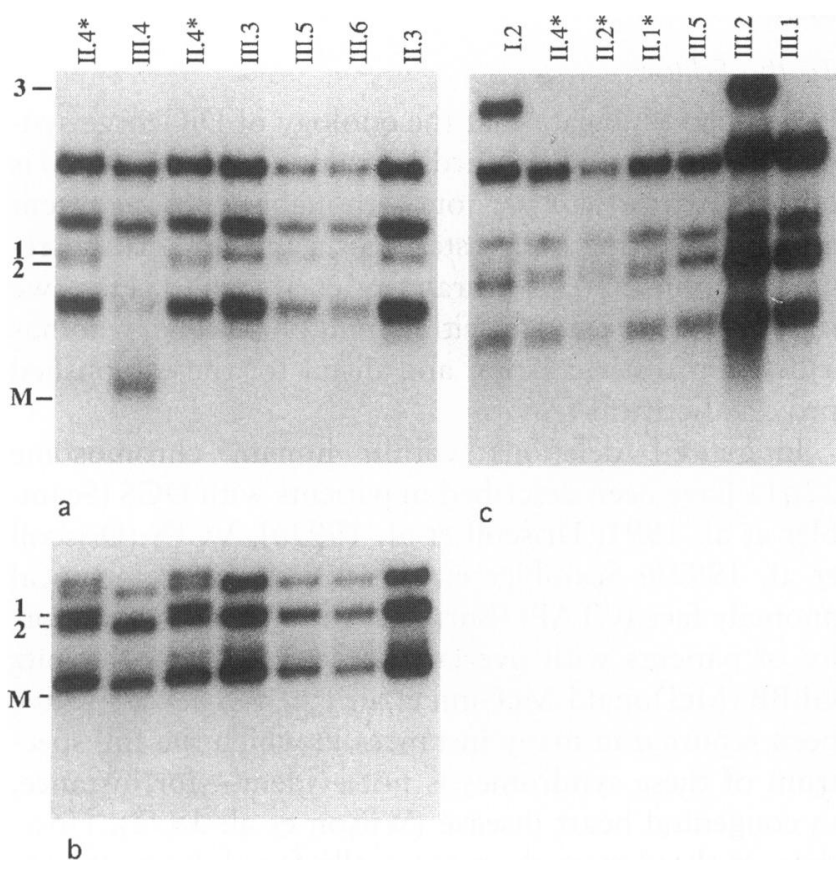

Figure 2 SSCP analysis of family Z. Analysis was performed as described elsewhere for exon c (Laporte et al. 1996) but with two different migration conditions at $4^{\circ} \mathrm{C}$ : slow migration at $5 \mathrm{~W}$ overnight ( $a$ and $c$ ) or fast migration for $5 \mathrm{~h}$ at $25 \mathrm{~W}(b)$. Alleles 1 and 2 are best separated under fast migration, whereas the mutation in III. 4 is detected only when slow migration is used $(a)$. Allele 3 is rare in the population studied (I.2 and III.2 [c]). rhabditis elegans. This striking conservation over a billion years, as well as the fact that this is a new mutation, support the contention that the amino acid change is indeed disease causing.

The finding of a new mutation present only in the proband contradicted our previous interpretation regarding carrier status. We thus reanalyzed the muscle biopsies taken from the different members of the family. A small percentage of muscle fibers with internally located nuclei indeed were found in the female biopsies (II.1, 2.4\%; II.2, 3.75\%; II.4, $1.2 \%$; and III.3, $0.8 \%$ ). However, a similar percentage also was found in the biopsy of the father of the propositus (II.3, $3.4 \%)$. These figures are, in fact, not very different from the generally accepted percentage of internally located nuclei in normal mature skeletal muscles. In the mother of the propositus, a moderate atrophy of the type II fibers also was found, with a few very small fibers with internal nuclei. Such findings appear to be nonspecific, but their interpretation in such a biopsy remains unclear.

In conclusion, our new findings remove any evidence for heterogeneity of X-linked myotubular myopathy, since we know of no other report of a discordant family. This means that the polymorphic markers very close to the MTM1 locus (Hu et al. 1996a, $1996 b)$ can be used, with increased confidence, for carrier and prenatal diagnosis in familial cases of MTM. In sporadic cases, accurate genetic counseling will require identification of the mutation. In particular, women at risk who, on the basis of the presence of fibers with centrally located nuclei, previously have been assigned a high carrier risk, should have their status carefully reinvestigated for the presence of a 


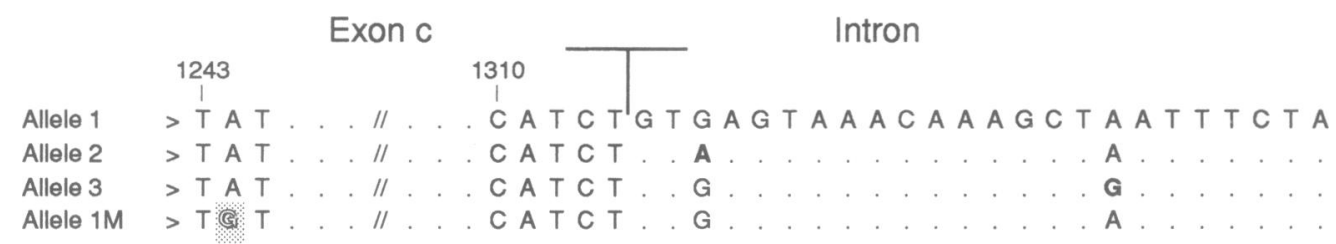

Figure 3 Sequence of alleles present in family Z. Alleles 1 and 2 differ at position +3 of the intron. Allele 3 differs, at intronic position +17 , from alleles 1 and 2 . The mutation A1244G is present on the background of allele 1 .

mutation. Finally, this case illustrates the danger, in linkage analysis, of overinterpreting slight phenotypic or pathological features, especially for carrier-status determination in X-linked diseases.

C. Guiraud-Chaumeil, ${ }^{1, *}$ M. C. VinCENT, ${ }^{2, *}$ J. LAPORTE, ${ }^{1}$ M. FARDEAU, ${ }^{3}$ F. SAMSON, ${ }^{4}$ AND J.-L. MANDEL ${ }^{1,2}$

${ }^{1}$ Institut de Génétique et de Biologie Moléculaire et Cellulaire/INSERM/CNRS/Université Louis Pasteur, Illkirch; ${ }^{2}$ Laboratoire de Génétique Moléculaire Humaine, Faculté de Médecine et CHRU, Strasbourg; ${ }^{3}$ INSERM U153, Institut de Myologie, Paris; and ${ }^{4}$ CNRS URA 1159, Le Plessis Robinson, France

\section{Acknowledgments}

This work was supported by Institut National de la Santé et de la Recherche Médicale (INSERM), the Centre National pour la Recherche Scientifique, Association Française contre les Myopathies, and the Centre Hospitalier Régional et Universitaire de Strasbourg.

\section{References}

Dahl N, Hu LJ, Chery M, Fardeau M, Gilgenkrantz S, Nivelon-Chevallier A, Sidaner-Noisette I, et al (1995) Myotubular myopathy in a girl with a deletion at Xq27-q28 and unbalanced $X$ inactivation assigns the MTM1 gene to a 600kb region. Am J Hum Genet 56:1108-1115

Hu LJ, Laporte J, Kioschis P, Heyberger S, Kretz C, Poustka A, Mandel JL, et al (1996a) X-linked myotubular myopathy: refinement of the gene to a $280-\mathrm{kb}$ region with new and highly informative microsatellite markers. Hum Genet 98: 178-181

Hu LJ, Laporte J, Kress W, Dahl N (1996b) Prenatal diagnosis of X-linked myotubular myopathy: strategies using new and tightly linked DNA markers. Prenat Diagn 16:231-237

Laporte J, Hu LJ, Kretz C, Mandel JL, Kioschis P, Coy JF, Klauck SM, et al (1996) A gene mutated in X-linked myotubular myopathy defines a new putative tyrosine phosphatase family conserved in yeast. Nat Genet 13:175-182

Samson F, Mesnard L, Heimburger M, Hanauer A, Chevallay M, Mercadier JJ, Pelissier JF, et al (1995) Genetic linkage heterogeneity in myotubular myopathy. Am J Hum Genet 57:120-126

Wallgren-Pettersson C, Clarke A, Samson F, Fardeau M, Du- bowitz V, Moser H, Grimm T, et al (1995) The myotubular myopathies: differential diagnosis of the $\mathrm{X}$ linked recessive, autosomal dominant, and autosomal recessive forms and present state of DNA studies. J Med Genet 32:673-679

Address for correspondence and reprints: Dr. Jean-Louis Mandel, IGBMC, B.P. 163, 67404 ILLKIRCH, CU de Strasbourg, France.

*These authors contributed equally to this work. (C) 1997 by The American Society of Human Genetics. All rights reserved. 0002-9297/97/6006-0035\$02.00

Am. J. Hum. Genet. 60:1544-1548, 1997

\section{Detection of an Atypical 22q11 Deletion That Has No Overlap with the DiGeorge Syndrome Critical Region}

To the Editor:

Recent data indicate that the etiology of DiGeorge syndrome (DGS) and velo-cardio-facial syndrome (VCFS) is more complex than previously thought, with one recent report suggesting the existence of a second "critical region" within 22q11 (Kurahashi et al. 1996). Here we report another patient, with a mild phenotype, who has a deletion distinct from, and distal to, the established proximal critical region.

Interstitial deletions within human chromosome $22 \mathrm{q} 11$ have been described in patients with DGS (Scambler et al. 1991; Driscoll et al. 1992a), VCFS (Driscoll et al. 1992b; Scambler et al. 1992), and conotruncal anomaly face (CTAF) (Burn et al. 1993) and in a minority of patients with overlap between VCFS and Opitz GBBB (McDonald-McGinn et al. 1995). They also have been reported in many instances in which the full spectrum of these syndromes is not evident-for instance, in congenital heart disease (Wilson et al. 1992). However, in these cases there is usually facial dysmorphism typical of that seen in VCFS. Since both mild and severe malformations, as well as birth defects affecting distinct organ systems, can occur in the same family, these various abnormalities are generally thought to share the same genetic etiology - namely, haploinsufficiency for a gene(s) within 22q11. 